\title{
Morphological, Transcriptomic and Hormonal Characterization of Trimonoecious and Subandroecious Pumpkin (Cucurbita maxima) Suggests Important Roles of Ethylene in Sex Expression
}

\author{
Yunli Wang ${ }^{1,2,+}$, Chundong Yan ${ }^{1,2,+}$, Bingxue Zou ${ }^{1,2}$, Chaojie Wang ${ }^{1,2}$, Wenlong Xu ${ }^{1,2}$, \\ Chongshi Cui ${ }^{1,2}$ and Shuping $Q u^{1,2, *}$ \\ 1 Key Laboratory of Biology and Genetic Improvement of Horticultural Crops (Northeast Region), \\ Ministry of Agriculture/Northeast Agricultural University, Harbin 150030, China \\ 2 College of Horticulture and Landscape Architecture, Northeast Agricultural University, \\ Harbin 150030, China \\ * Correspondence: spqu@neau.edu.cn \\ + These authors contributed equally to this work and should be considered co-first authors.
}

Received: 21 May 2019; Accepted: 26 June 2019; Published: 28 June 2019

check for updates

\begin{abstract}
Sex expression is a complex process, and in-depth knowledge of its mechanism in pumpkin is important. In this study, young shoot apices at the one-true-leaf stage and 10-leaf stage in Cucurbita maxima trimonoecious line '2013-12' and subandroecious line '9-6' were collected as materials, and transcriptome sequencing was performed using an Illumina HiSeq ${ }^{\mathrm{TM}} 2000$ System. 496 up-regulated genes and 375 down-regulated genes were identified between shoot apices containing mostly male flower buds and only female flower buds. Based on gene ontology (GO) and Kyoto Encyclopedia of Genes and Genomes (KEGG) analysis, the differentially expressed genes were mainly enriched in the ethylene and auxin synthesis and signal transduction pathways. In addition, shoot apices at the 4-leaf stage were treated with the ethylene-releasing agent 2-chloroethylphosphonic acid (Ethrel), aminoethoxyvinyl glycine (AVG), $\mathrm{AgNO}_{3}$ and indoleacetic acid (IAA). The number of female flowers up to node 20 on the main stem of '2013-12' increased significantly after Ethrel and IAA treatment and decreased significantly after $\mathrm{AVG}$ and $\mathrm{AgNO}_{3}$ treatment. The female flowers in '9-6' showed slight changes after treatment with the exogenous chemicals. The expression of key genes in ethylene synthesis and signal transduction (CmaACS7, CmaACO1, CmaETR1 and CmaEIN3) was determined using quantitative RT-PCR, and the expression of these four genes was positively correlated with the number of female flowers in '2013-12'. The variations in gene expression, especially that of CmaACS7, after chemical treatment were small in '9-6'. From stage 1 (S1) to stage 7 (S7) of flower development, the expression of CmaACS7 in the stamen was much lower than that in the ovary, stigma and style. These transcriptome data and chemical treatment results indicated that IAA might affect pumpkin sex expression by inducing CmaACS7 expression and indirectly affecting ethylene production, and the ethylene synthesis and signal transduction pathways play crucial roles in pumpkin flower sex expression. A possible reason for the differences in sex expression between pumpkin lines '2013-12' and ' $9-6$ ' was proposed based on the key gene expression. Overall, these transcriptome data and chemical treatment results suggest important roles for ethylene in pumpkin sex expression.
\end{abstract}

Keywords: Cucurbita maxima; transcriptome sequencing; floral sex expression; ethylene signal synthesis and transduction; chemical treatment 


\section{Introduction}

In flowering plants, sex expression is an important process that differentiates male and female flowers. Many factors are involved in the complex process of sex expression, such as temperature, daylength, ethylene, auxin, cytokinin, brassinolide (BR) and nitrogen metabolism [1]. In addition to environmental factors, key genes also play a crucial role in sex determination. In the Cucurbitaceae, such as melon (Cucumis melo L.) and cucumber (Cucumis sativus L.), floral primordia are initially bisexual, and sex determination occurs by developmental arrest of either the stamen or the carpel whorl, resulting in unisexual flowers [2]. Genes specifically expressed in the stamen or carpel primordia control the development of male, female, and hermaphrodite flowers [3-6].

Because the Cucurbitaceae includes seven sex forms, it is a model dicotyledonous plant family for sex determination research. The sex determination mechanism of Cucurbitaceae has been thoroughly studied, and ethylene is a key hormone that promotes female flower development in Cucurbitaceae plants. The enzymes 1-aminocyclopropane-1-carboxylate (ACC) synthetase (ACS), which catalyzes the rate-limiting step in ethylene biosynthesis, and ACC oxidase (ACO), which converts ACC into ethylene, are key in ethylene biosynthesis [7]. The genes CSACS2 (the $M$ (andromonoecious) loci in cucumber), CmACS7 (the M loci in melon), ClACS7 and CitACS4 can inhibit stamen development in female flowers and determine andromonoecy [3,4,8-12]. CsACS11 (the A (androecy) loci in cucumber) and CmACS11 loss-of-function mutants lead to male plants [5,10]. Cucumber plants harboring CsACS1G (the $F$ (female) loci) bear only female flowers, although the molecular mechanisms remain to be investigated $[6,13]$. CitACS4 is expressed specifically in carpel primordia in watermelon (Citrullus lanatus sp.), which indicates that CitACS4 also plays a role in sex determination [12]. CsACO2 is essential for carpel development and interacts with CSACS11 to promote female flower development in cucumber [14].

Ethylene signaling is perceived by a family of ethylene receptors. CS-ETR2 and CS-ERS, which are ethylene receptor-related genes, may play roles in the development of female flowers in gynoecious cucumbers under high levels of endogenous ethylene [15]. ETR1 is known as the negative ethylene perception gene. CSETR1 was demonstrated to be involved in stamen development in female cucumber flowers through the induction of DNA damage [16]; etr1-1 transgenic melon plants had a higher number and earlier appearance of carpel-bearing flowers on the main stem. This phenomenon indicates that ETR1 also plays a role in sex determination in melon. Recently, with the help of yeast one-hybrid and ChIP-PCR assays, CsERF110 (ethylene-responsive factor 110) and CmERF110 were shown to respond to ethylene signaling and enhance CSACS11 and CmACS11 promoter activity in cucumber and melon [17]. CSERF31 (ethylene-responsive factor 31) also responded to the ethylene signal derived from $F$ and positively regulated ethylene feedback by activating $M$ expression in cucumber [18].

Pumpkin, a monoecious plant that belongs to the genus Cucurbita, is an annual vine. Pumpkin includes the three most economically important cultivated species, pumpkin (Cucurbita maxima Duch.), zucchini (Cucurbita pepo L.) and squash (Cucurbita moschata Duch.). Hybrids show strong heterosis, but hybrid production requires cross-pollination every year. Therefore, it is necessary to manually remove males, which takes time and effort. Thus, it is important to explore the sex determination mechanism of pumpkin to provide a basis for pumpkin cultivation techniques. Typical monoecious pumpkin varieties have three different developmental phases: only male flowers are produced in the first phase, the production of female and male flowers alternates during the second phase, and only female flowers are produced in the third phase [19]. According to genetic and physiological analyses of sex expression, the androecious phenotype of C. pepo is determined by a single recessive gene [20], while gynoecious form is a dominant characteristic [21]. Androecious C. pepo is ethylene insensitive, and this trait is controlled by an ethylene-response pathway gene named weak ethylene insensitive (CPWEI) [22,23]. Two constitutive triple response (CTR) genes, CPCTR1 and CPCTR2, were cloned as negative regulators of ethylene signaling in flowers [24]. Through transcriptional regulation analysis, ethylene receptor and CTR-like genes were confirmed as negative regulators of female flower transition during the earlier stages of plant development [25]. In addition, CpACS27A, a gene homologous to CmACS7 and CsACS2, was cloned and observed to regulate stamen development in C. pepo [26]. In recent years, a strong female developmental 
gene in C. maxima was mapped to an interval of $35.2 \mathrm{~Kb}$, and the possible candidate gene was identified as a pentatricopeptide repeat-containing family gene [27].

RNA sequencing (RNA-seq) is a useful transcriptome profiling tool for rapid gene discovery, exploring gene expression, elucidating phylogenetic relationships, molecular marker development and related gene expression analyses that has been used in Cucurbita species [28-30]. In 2011, the first Cucurbita transcriptome was generated using 454 GS FLX Titanium technology [28]. Subsequently, many differentially expressed genes associated with flowering, disease resistance, fruit size, fruit shape, fruit color, fruit sweetness, fruit nutritional qualities, and chilling sensitivity were determined using RNA-seq [29,31-36].

The sex expression mechanism in pumpkin is less well known than that in other Cucurbitaceae species, such as cucumber and melon. Therefore, in this study, RNA-seq was carried out using subandroecious and trimonoecious C. maxima as materials, and differentially expressed genes involved in the ethylene synthesis and signal transduction pathways were identified. The number of female flowers in trimonoecious $C$. maxima changed significantly after 4 chemical treatments, and the expression levels of CmaACS7, CmaACO1, CmaETR1 and CmaEIN3 were positively correlated with the number of female flowers. The number of female flowers in subandroecious C. maxima changed slightly, and the variations in gene expression, especially that of CmaACS7, were small in amplitude. The expression of CmaACS7 in the ovary, stigma and style at different stages of flower development indicated that CmaACS7 plays an important role in sex differentiation. The transcriptome data and results of chemical treatment indicated that the ethylene synthesis and signal transduction pathways play a crucial role in pumpkin flower sex expression.

\section{Results}

\subsection{Flower Phenotype}

Flowers on the main stem of the subandroecious line ' $9-6$ ' were mainly male unisexual flowers; however, one or two female flowers appeared at nodes $15-16$; fewer than $10 \%$ female flowers were observed up to node 20 of the main stem. Several male and bisexual flowers were present at the base of the main stem in the trimonoecious line ' $2013-12$ ', and all flowers produced after the first female flower, which appeared at node 10, were female unisexual flowers. The female flower proportion of '2013-12' was approximately 50\% up to node 20 on the main stem (Figure 1). Considering pumpkin hybrid production, the seed production process could be simplified by using the '2013-12' inbred line.
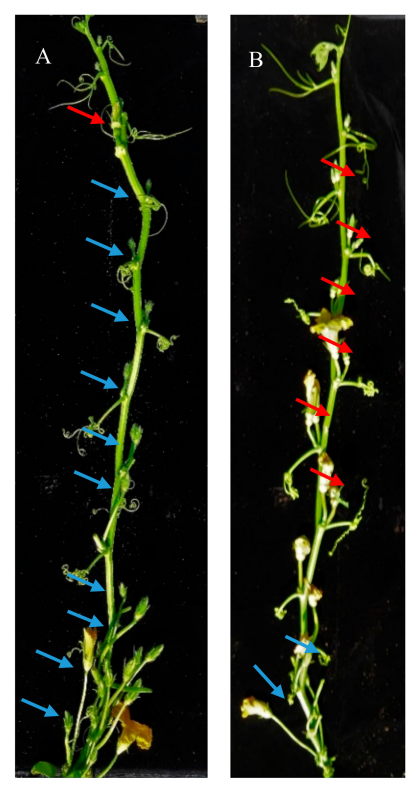

Figure 1. Different flower phenotype of two materials. (A) Flower phenotype of '9-6'. (B) Flower phenotype of '2013-12'. '9-6' and '2013-12' produced female flowers $4 \%$ and $51 \%$ respectively when observed up to node 20 on the main stem. Blue arrows indicated male flowers and red arrows indicated female flowers. 


\subsection{RNA-Seq of Pumpkin}

In '9-6', shoots at one-true-leaf stage (LS1) (MS1-type sample) contained only male flower buds, whereas those at 10-leaf stage (LS10) (MS10-type sample) contained male flower buds and one or two female flower buds. In '2013-12', shoots at LS1 (FS1-type sample) contained male flower buds and one or two bisexual flower buds, and those at LS10 (FS10-type sample) contained only female flower buds. There were obvious sex expression differences in FS1 vs. FS10 and in MS10 vs. FS10, but no significant differences were observed in MS1 vs. MS10 and MS1 vs. FS1.

In this research, the molecular mechanism of sex expression was explored using an RNA-seq approach; young shoots of '2013-12' and ' $9-6$ ' at the LS1 stage and LS10 stage were used as materials. Through sequencing, a total of $525.41 \mathrm{Mb}$ raw reads and $509.23 \mathrm{Mb}$ clean reads, which showed valid bases from $96.22 \%$ to $97.17 \%$, were obtained. In the clean reads of all 12 samples, the Q30 scores ranged from $93.89 \%$ to $94.60 \%$, and the GC content ranged from $44.5 \%$ to $45 \%$ (Table 1), which demonstrated that high-quality sequencing results were obtained for further research.

Table 1. Summary statistics of RNA sequencing (RNA-seq).

\begin{tabular}{cccccccc}
\hline $\begin{array}{c}\text { Sample } \\
\text { ID }\end{array}$ & $\begin{array}{c}\text { Raw Reads } \\
\mathbf{( M b )}\end{array}$ & $\begin{array}{c}\text { Raw Bases } \\
\mathbf{( G b )}\end{array}$ & $\begin{array}{c}\text { Clean } \\
\text { Reads } \mathbf{( M b )}\end{array}$ & $\begin{array}{c}\text { Clean Bases } \\
\mathbf{( G b )}\end{array}$ & $\begin{array}{c}\text { Valid } \\
\text { Bases } \mathbf{( \% )}\end{array}$ & Q30 (\%) & GC (\%) \\
\hline MS1.1 & 38.21 & 4.78 & 37.06 & 4.63 & 96.95 & 94.29 & 45 \\
MS1.2 & 43.52 & 5.44 & 42.17 & 5.27 & 96.86 & 94.57 & 45 \\
MS1.3 & 46.69 & 5.84 & 45.39 & 5.67 & 97.16 & 94.60 & 45 \\
MS10.1 & 46.31 & 5.79 & 44.96 & 5.62 & 97.05 & 94.55 & 45 \\
MS10.2 & 43.91 & 5.49 & 42.54 & 5.32 & 96.84 & 94.47 & 45 \\
MS10.3 & 42.03 & 5.25 & 40.70 & 5.09 & 96.81 & 94.28 & 45 \\
FS1.1 & 48.34 & 6.04 & 46.86 & 5.86 & 96.90 & 94.49 & 45 \\
FS1.2 & 45.03 & 5.63 & 43.67 & 5.46 & 96.95 & 94.51 & 45 \\
FS1.3 & 47.38 & 5.92 & 45.86 & 5.73 & 96.75 & 94.46 & 45 \\
FS10.1 & 43.06 & 5.38 & 41.86 & 5.23 & 97.17 & 94.71 & 45 \\
FS10.2 & 38.27 & 4.78 & 36.83 & 4.6 & 96.22 & 93.89 & 44.5 \\
FS10.3 & 42.65 & 5.33 & 41.33 & 5.16 & 96.87 & 94.60 & 44.5 \\
\hline
\end{tabular}

All clean reads were subsequently subjected to de novo assembly with the Trinity program and produced 747,168 unigenes with a total length of $969.15 \mathrm{Mb}$. The average number of unigenes was $1297.09 \mathrm{bp}$. Of these, the longest unigene was 20,293 bp, and the shortest unigene was $201 \mathrm{bp}$ (Table S1). Approximately $81.34-82.78 \%$ of clean reads could be mapped to the reference genome (Table S2). A total of 131,960 unigenes (17.66\%) were annotated based on the information available from five public protein databases, i.e., the NR, Swiss-Prot, KOG, GO and Kyoto Encyclopedia of Genes and Genomes (KEGG) databases, using BLAST with an E-value cut-off of $1.0 \mathrm{e}^{-5}$. In total, 57,118 unigenes, $43.28 \%$ of the total assembled unigenes, were matched in the NR database, and 38,487 (29.17\%), 32,257 $(24.44 \%), 13,828(10.48 \%)$, and $33,927(25.71 \%)$ of the unigenes were matched in the Swiss-Prot, KOG, GO and KEGG databases, respectively.

The correlation of gene expression between samples is important to test the reliability of the database and the rationality of sample selection. According to the unigene expression level, the correlation coefficients between replicate samples were approximately 1 (Figure 2A), and the PCA results showed that the three biological replicates of each sample type were clustered together (Figure 2B). Similar results were obtained through gene expression distance analysis (Figure S1). Overall, the similarity of expression profiles and the high correlation between replicates indicated high data reliability of the high-throughput sequencing and reproducible replicate samples in this study. 

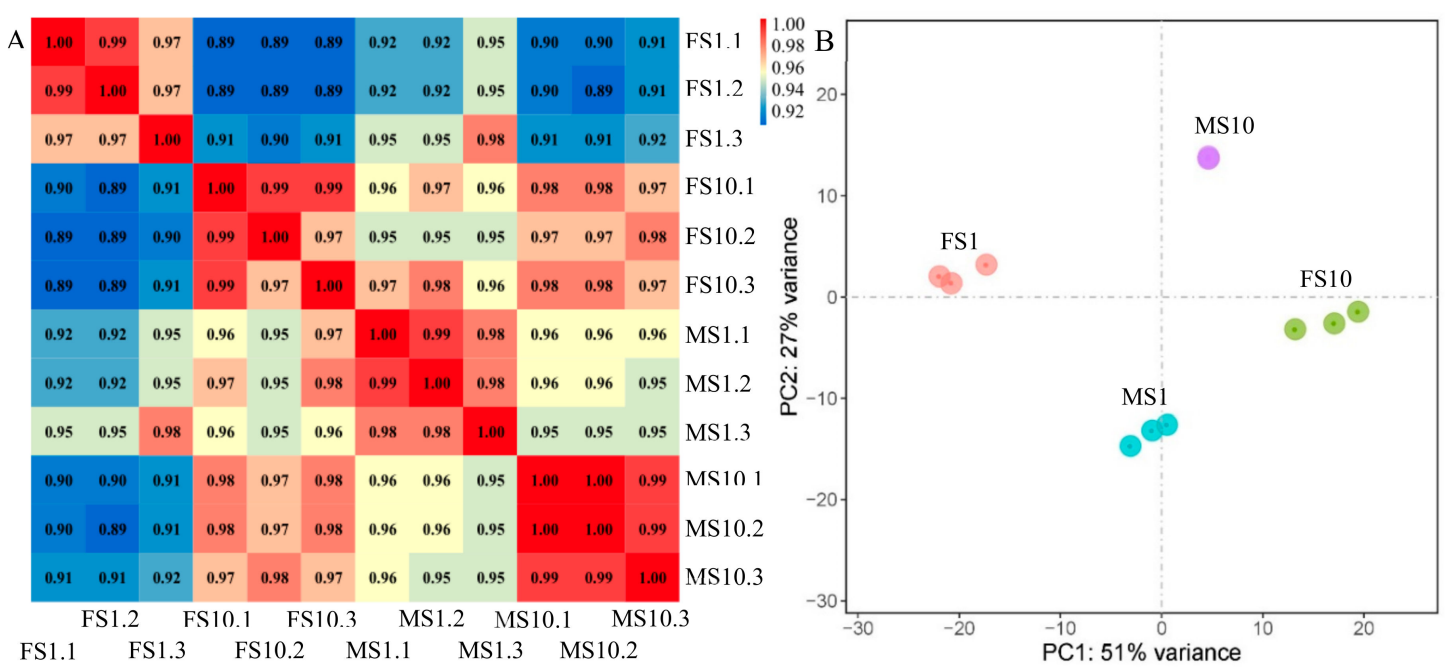

Figure 2. Correlation analysis and principal component analysis of samples. (A) Correlation analysis of gene expression between samples. Comparisons of gene expression between replicates on the x-axis and those on the y-axis. The correlation coefficients between replicate samples were approximately 1 . The correlation coefficient was show as a color value (blue: less similar, and red: more similar). (B) Principal component analysis plot of RNA sequencing (RNA-seq) data in samples. Three biological replicates for each sample type were clustered together. Blue plots indicated samples of ' $9-6$ ' at one-true-leaf stage (LS1) (MS1), purple plots indicated samples of '9-6' at 10-leaf stage (LS10) (MS10), pink plots indicated samples of '2013-12' at LS1 (FS1), and green plots indicated samples of '2013-12' at LS10 (FS10).

\subsection{Differential Expression Analysis and Functional Annotation}

To characterize transcriptional variations that occur in response to sex determination, the transcripts between two different sample types were compared, and the number of differentially expressed genes (DEGs) including $>$ two-fold up-regulation or $>$ two-fold down-regulation was counted. $\log _{2}$ FoldChange and $p$-value of DEGs between two sample types (FS1 vs. MS1, FS10 vs FS1, MS10 vs. MS1, FS10 vs. MS10) were listed in Non-published Material 1. As shown in Figure 3, 2306 genes were differentially expressed in MS1 vs. MS10 (977 were up-regulated and 1329 were down-regulated), 3764 genes were differentially expressed in FS1 vs. FS10 (1436 up-regulated and 2328 down-regulated), 1874 genes were differentially expressed in MS1 vs. FS1 (1293 up-regulated and 581 down-regulated), and 1312 genes were differentially expressed in MS10 vs. FS10 (834 up-regulated and 478 down-regulated). A total of 4327 DEGs were sample-specific. Amounts of 414, 218, 99 and 1400 DEGs were specifically down-regulated expressed, while 327, 882, 309 and 678 DEGs were specifically up-regulated expressed in the MS1 vs. MS10, MS1 vs. FS1, MS 10 vs. FS1 and FS1 vs FS10 comparisons, respectively (Figure 4). In total, 871 DEGs (496 up-regulated and 375 down-regulated) were differentially expressed in both FS1 vs. FS10 and MS10 vs. FS10 and were not differentially expressed in MS1 vs. MS10 or MS1 vs. FS1. These genes showed tissue-specific expression between shoot apices containing male flower buds and female flower buds, which indicated that these genes may be involved in sex determination.

To further characterize the genes identified as being differentially expressed in association with sex, 871 DEGs were mapped to GO classifications, and KEGG enrichment was determined. The GO annotations of the DEGs are shown in Figure 5. The main functional groups of the up-regulated genes are related to floral organ formation, mitogen-activated protein kinase (MAPK) cascade, floral organ development, specification of carpel identity and floral meristem determinacy. The main functional groups of the down-regulated genes are related to photosynthesis regulation, the auxin-activated signaling pathway, wounding, phloem development and other processes. The 20 most highly represented pathways of the 871 DEGs are shown in Figure 6. The DEGs were mainly enriched in plant hormone signal transduction, stilbenoid, diarylheptanoid and gingerol biosynthesis, flavonoid biosynthesis, phenylpropanoid biosynthesis, nitrogen metabolism and other pathways. The majority 
of the DEGs were involved in plant hormone signal transduction pathway (largest point in Figure 6), and the expression of these DEGs was significantly expression between the shoot apices contained different number of female flower buds (red point, which indicated $p$-value $<0.001$ ). The expressed of these DEGs was significantly different between the shoot apices containing different numbers of female flower buds (red point, which indicated $p$-value $<0.001$ ). This result indicated that pumpkin floral organ formation in the main stem is controlled through changes in the transcript levels of key genes involved in hormone signal transduction.
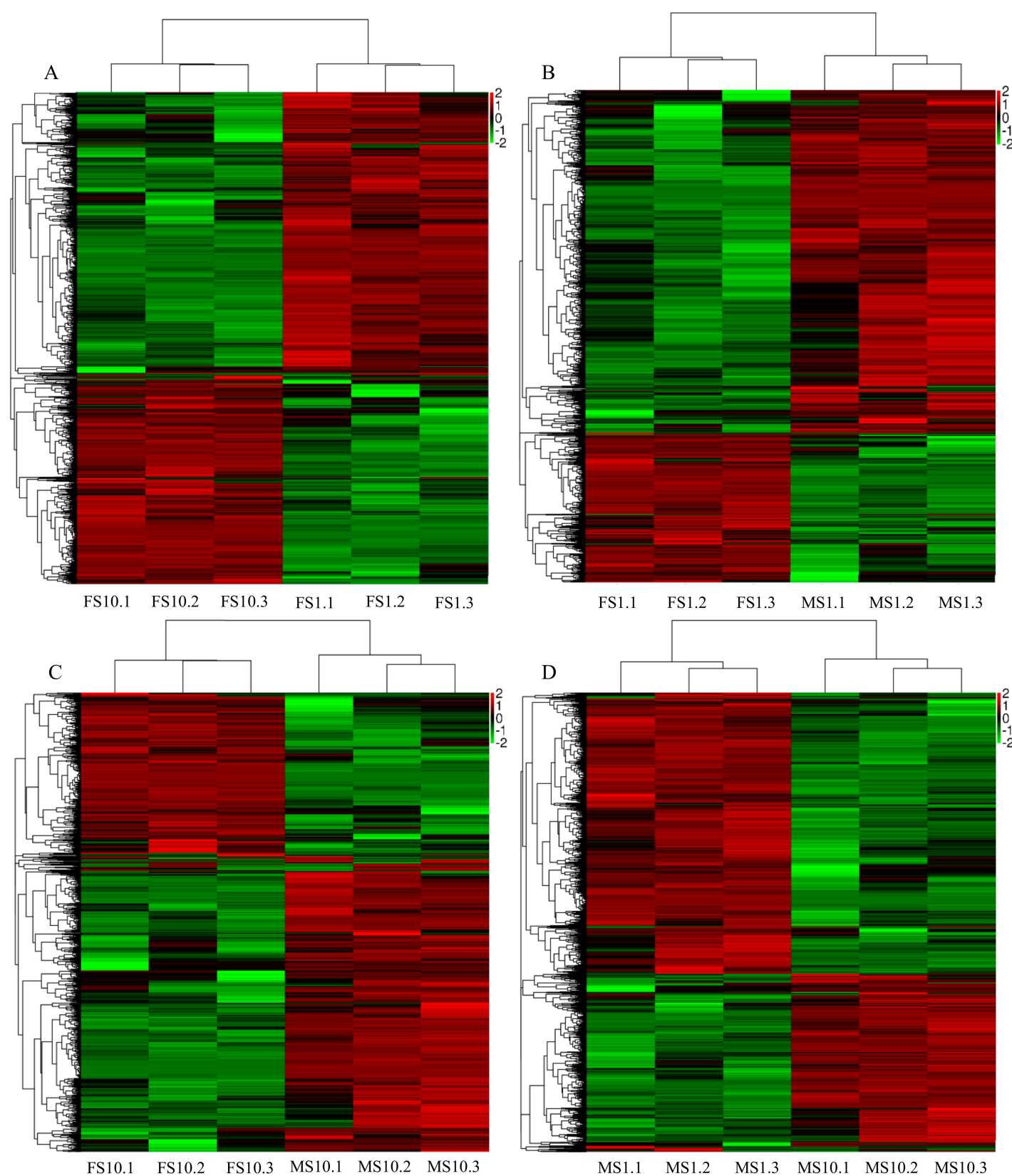

Figure 3. Heatmap visualization of expression profiles of MS1, MS10, FS1 and FS10. (A) Heatmap visualization of expression profiles between FS1 and FS10. (B) Heatmap visualization of expression profiles between FS1 and MS1. (C) Heatmap visualization of expression profiles between FS10 and MS10. (D) Heatmap visualization of expression profiles between MS1 and MS10. Red arrow, > two-fold up-regulation; green arrow, > two-fold down-regulation. 

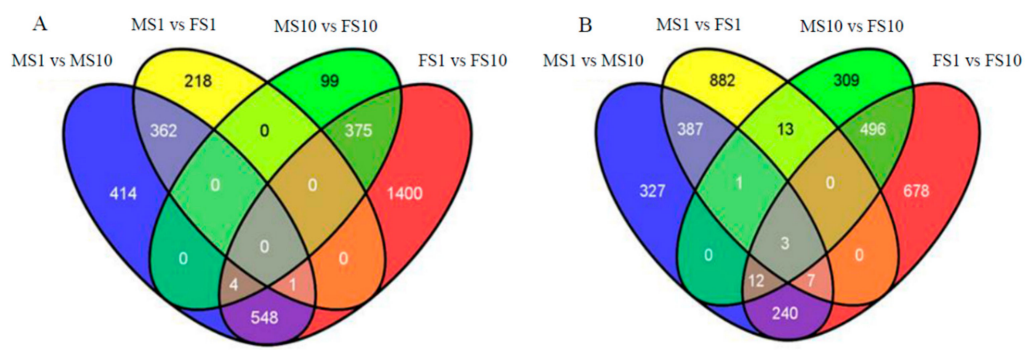

Figure 4. Number of differentially expressed genes among MS1, MS10, FS1 and FS10. (A) Number of down-regulated expressed genes. (B) Number of up-regulated expressed genes. MS1 indicated samples of '9-6' at LS1, MS10 indicated samples of '9-6' at LS10, FS1 indicated samples of '2013-12' at LS1, and FS10 indicated samples of '2013-12' at LS10.

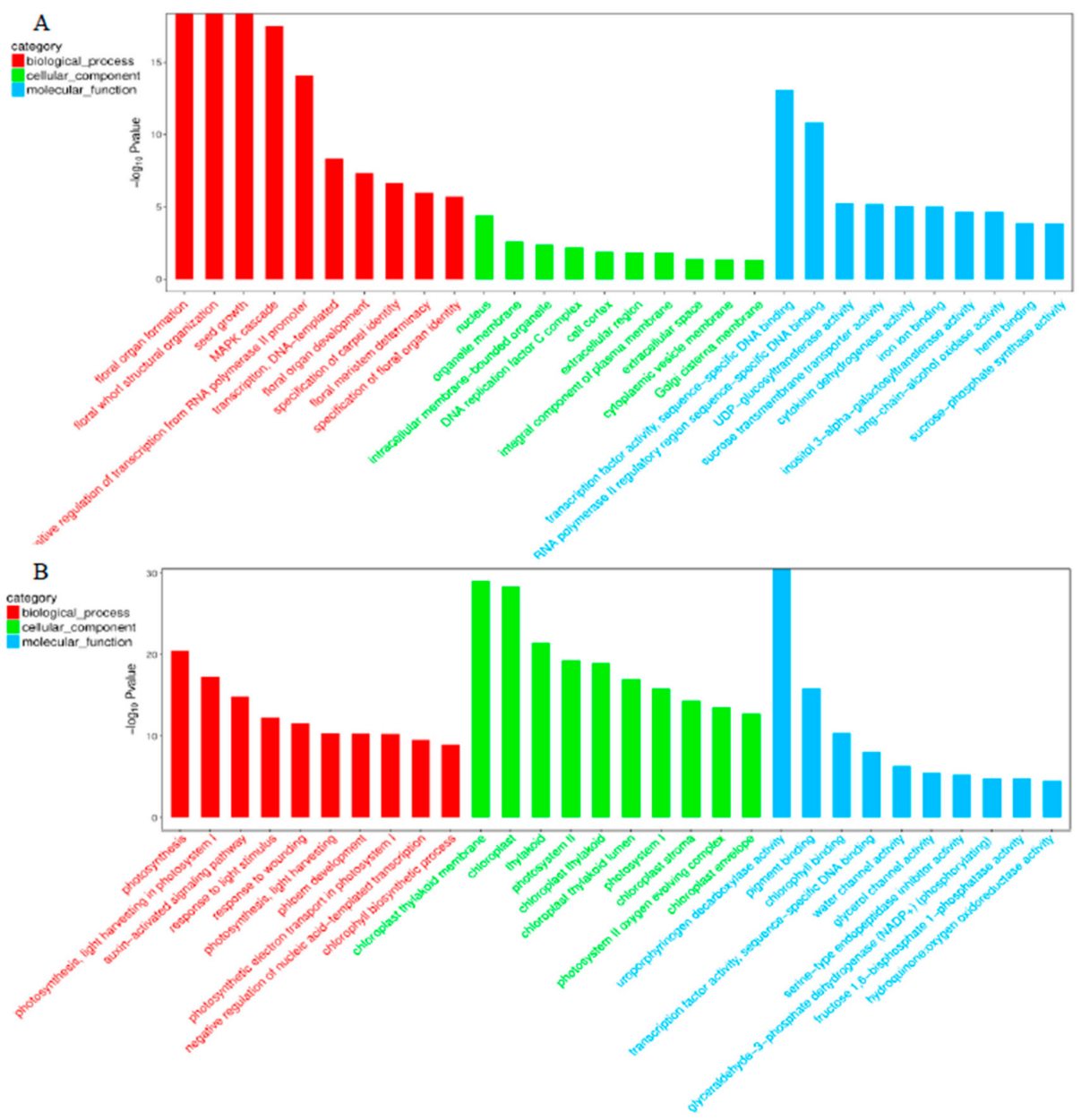

Figure 5. The gene ontology classification of up-regulated genes (A) and down-regulated genes (B) between young shoot apices containing male flower buds and female flower buds.

To further test the reliability of RNA-seq, 17 genes were randomly selected from the 871 DEGs based on sequencing, and quantitative reverse transcription polymerase chain reaction (qRT-PCR) analysis was performed with specific primers using FS1 and FS10 samples. The results showed that the gene expression patterns of FS1 vs. FS10 examined by qRT-PCR analyses were similar to those revealed by RNA-seq (Figure 7A). Most of the expression patterns shown by qRT-PCR agreed with the RNA-seq ratios, with a relative coefficient of $R^{2}=0.9$ (Figure 7B). 


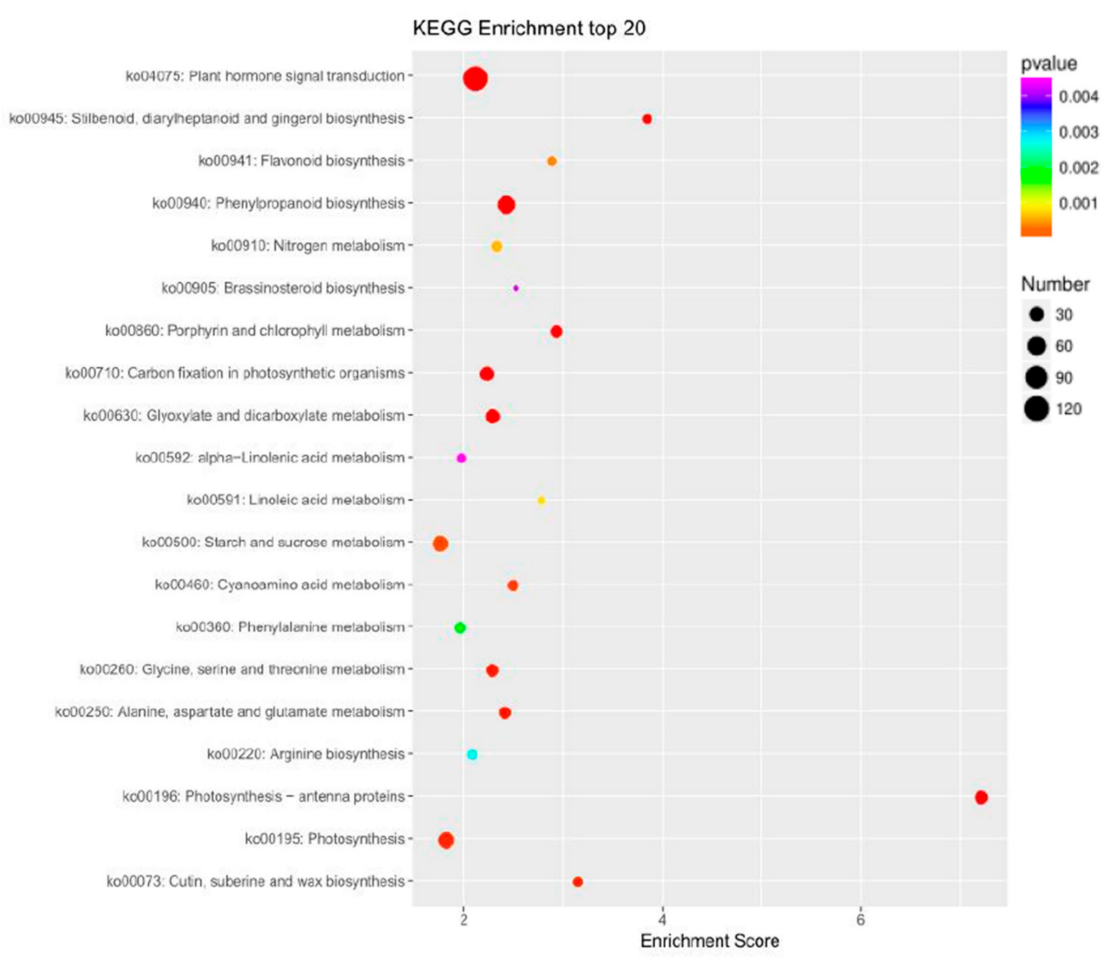

Figure 6. Kyoto Encyclopedia of Genes and Genomes (KEGG) pathway scatterplot of 871 differentially expressed genes (DGEs). The $x$-axes indicate enrichment score. The bigger the bubble, the more the DGEs. The smaller the p-value, the more significant the KEGG enrichment.
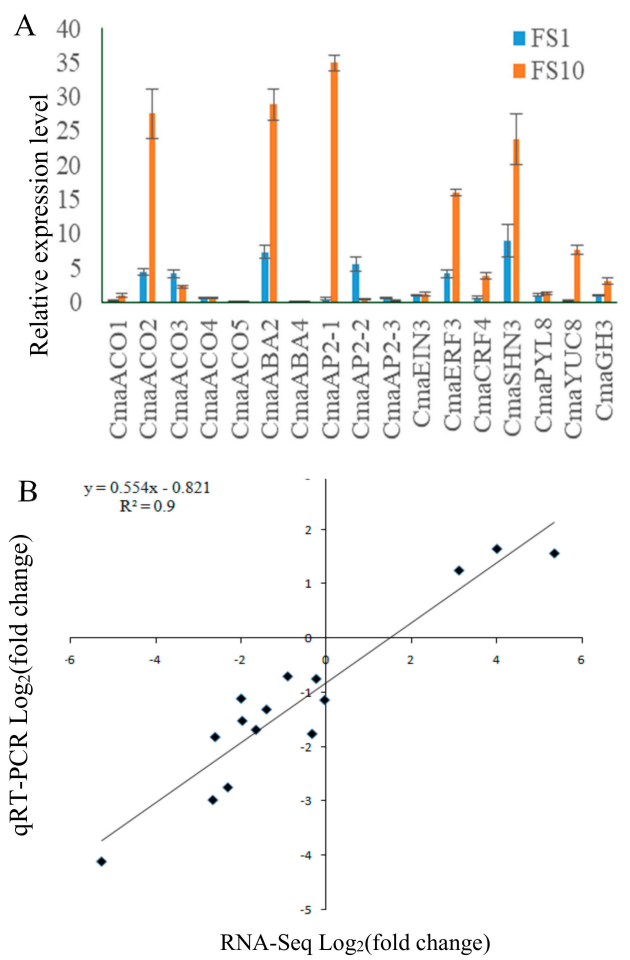

Figure 7. Expression comparison of 17 selected genes using RNA-seq and quantitative reverse transcription polymerase chain reaction (qRT-PCR). (A) Relative expression of 17 selected genes in FS1 and FS10 using qRT-PCR. The CmaACO1 expression at FS10 was assumed as 1. Data are displayed as the ratio of expression to CmaActin with three biological replicates. Error bars represent standard error (SE). The qRT-PCR of primers used are given in Table S3. (B) Comparison of the expression ratios of 17 selected genes in '2013-12' at LS1 and LS10 stage using RNA-seq and qRT-PCR. 


\subsection{Hormone Genes Associated with Sex Expression}

According to the KEGG pathway results, the majority of DEGs were enriched in the plant hormone signal transduction pathway related to ethylene synthesis and signal transduction. Based on $\log _{2}$-fold change $>1$ or $<-1$ in FS1 vs. FS10 and MS10 vs. FS10 as specific queries, 25 DEGs are listed in Table 2. Two genes are associated with ethylene synthesis, and 23 genes are associated with the ethylene signaling pathway. Among these 23 genes, six are also associated with auxin, abscisic acid, cytokinin, gibberellin, jasmonic acid and salicylic acid. Ethylene synthesis genes and most positively regulated ethylene signaling genes were up-regulated, and three negatively regulated ethylene signaling genes (CmaCh01G009990, CmaCh01G016830 and CmaCh09G005960) were down-regulated in FS10. These results indicated that genes related to ethylene synthesis and signal transduction positively regulate female sex expression in pumpkin. Two ethylene synthesis genes, CmaCh03G005620 and CmaCh02G000660, were analyzed for expression in different organs. CmaCh02G000660 (named CmaACO1) showed flower-specific expression and significantly differential expression between female and male flowers (Non-published Material 2), so we selected it for further study.

Table 2. Differentially expressed genes related to ethylene synthesis and signal transduction in one-'2013-12' one-true-leaf stage sample (FS1) vs. 10-leaf stage sample (FS10) and '6-9' one-true-leaf stage (MS10) vs. FS10.

\begin{tabular}{|c|c|c|c|}
\hline Gene ID & $\begin{array}{l}\text { FS1 VS FS10 } \\
\log _{2} \text { FoldChange }\end{array}$ & $\begin{array}{l}\text { MS10 VS FS10 } \\
\log _{2} \text { FoldChange }\end{array}$ & GO Term \\
\hline CmaCh03G005620 & 1.14 & 1.18 & 1-aminocyclopropane-1-carboxylate oxidase \\
\hline CmaCh02G000660 & 2.75 & 0.26 & 1-aminocyclopropane-1-carboxylate oxidase \\
\hline CmaCh01G009990 & -1.43 & -0.16 & $\begin{array}{c}\text { negative regulation of ethylene-activated signaling pathway, } \\
\text { auxin efflux transmembrane transporter activity, auxin } \\
\text { homeostasis, auxin polar transport, auxin-activated signaling } \\
\text { pathway }\end{array}$ \\
\hline CmaCh01G016830 & -1.25 & -0.44 & $\begin{array}{l}\text { negative regulation of ethylene-activated signaling pathway, } \\
\text { regulation of abscisic acid-activated signaling pathway, } \\
\text { cytokinin-activated signaling pathway }\end{array}$ \\
\hline CmaCh02G014030 & 1.82 & 1.32 & $\begin{array}{c}\text { ethylene-activated signaling pathway, cytokinin-activated } \\
\text { signaling pathway }\end{array}$ \\
\hline CmaCh04G006970 & 2.74 & 1.42 & ethylene-activated signaling pathway \\
\hline CmaCh04G002620 & 1.87 & 0.15 & ethylene-activated signaling pathway \\
\hline CmaCh04G012360 & 1.69 & 0.44 & ethylene-activated signaling pathway \\
\hline CmaCh04G020120 & 2.35 & 0.07 & ethylene-activated signaling pathway \\
\hline CmaCh04G008070 & -1.66 & -0.36 & ethylene-activated signaling pathway \\
\hline CmaCh04G015210 & 1.81 & 0.74 & ethylene-activated signaling pathway \\
\hline CmaCh04G004940 & Inf & Inf & ethylene-activated signaling pathway \\
\hline CmaCh05G004890 & 1.08 & 0.3 & $\begin{array}{c}\text { ethylene-activated signaling pathway, cytokinin-activated } \\
\text { signaling pathway }\end{array}$ \\
\hline CmaCh05G001690 & 1.40 & 0.10 & ethylene-activated signaling pathway \\
\hline CmaCh07G005340 & 2.45 & 0.70 & ethylene-activated signaling pathway \\
\hline CmaCh09G004610 & 1.31 & 0.42 & ethylene-activated signaling pathway \\
\hline CmaCh09G005960 & -3.13 & -0.82 & $\begin{array}{c}\text { negative regulation of ethylene-activated signaling pathway, } \\
\text { gibberellin biosynthetic process }\end{array}$ \\
\hline CmaCh09G008010 & 2.02 & 1.57 & response to jasmonic acid and salicylic acid \\
\hline CmaCh10G006590 & 1.34 & 0.04 & ethylene-activated signaling pathway \\
\hline CmaCh11G006380 & 1.38 & 0.49 & ethylene-activated signaling pathway \\
\hline CmaCh11G008140 & 1.01 & 0.11 & ethylene-activated signaling pathway \\
\hline CmaCh11G019380 & 1.17 & 0.42 & negative regulation of ethylene-activated signaling pathway \\
\hline CmaCh11G005470 & 1.09 & 0.20 & ethylene-activated signaling pathway \\
\hline CmaCh17G008890 & 2.32 & 0.86 & ethylene-activated signaling pathway \\
\hline CmaCh19G010510 & 1.53 & 0.12 & negative regulation of ethylene-activated signaling pathway \\
\hline
\end{tabular}

\subsection{Plant Phenotypes after Chemical Treatments}

To further demonstrate the effects of ethylene and auxin on the sex expression of pumpkin, shoot apices were treated with four chemicals: Ethrel, aminoethoxyvinyl glycine (AVG), $\mathrm{AgNO}_{3}$ and indoleacetic acid (IAA). Table 3 shows the effects of these chemicals on sex expression in '9-6' and '2013-12'. The subandroecious ' $9-6$ ' control produced female flowers on $4 \%$ of the 20 nodes, and 
the first female node was node 15.4. There was no obvious increase or decrease in the number of female flowers, and the appearance of female flowers was not significantly advanced or delayed after Ethrel, IAA, AVG or $\mathrm{AgNO}_{3}$ treatment compared with the control. The trimonoecious '2013-12' control produced female flowers at $51 \%$ of the 20 nodes and bisexual flowers at $27.5 \%$ of the nodes, and the first female node was node 10.1. When Ethrel was applied to the shoot apices at the four-leaf stage, female flowers were produced at $72.5 \%$ of the nodes, and bisexual flowers were produced at $3 \%$ of the nodes. The first female node was node 5.9 , implying a significant increase in female flower development and a significant decrease in bisexuality as well as a distinctly early appearance of female flowers relative to the control. IAA treatment exerted a similar effect to Ethrel. When $\mathrm{AgNO}_{3}$ was applied, female flowers were produced at $33.5 \%$ and bisexual flowers were produced at $33.5 \%$ of the nodes, and the first female node was node 13.7, implying a significant decrease in female flower development. AVG treatment had a similar effect to that of $\mathrm{AgNO}_{3}$.

Table 3. Effects of different hormone treatments on sex differentiation of '2013-12' and '9-6'.

\begin{tabular}{ccccccc}
\hline \multirow{2}{*}{ Treatment } & \multicolumn{2}{c}{ Female Flowers Per Plant \% } & \multicolumn{2}{c}{ First Female Flower Node } & \multicolumn{2}{c}{ Bisexual Flowers Per Plant \% } \\
& $\mathbf{2 0 1 3 - 1 2}$ & $\mathbf{9 - 6}$ & $\mathbf{2 0 1 3 - 1 2}$ & $\mathbf{9 - 6}$ & $\mathbf{2 0 1 3 - 1 2}$ & $\mathbf{9 - 6}$ \\
\hline Ethrel & $72.5 \pm 3.5 \mathrm{a}$ & $5 \pm 1 \mathrm{a}$ & $5.9 \pm 0.4 \mathrm{c}$ & $13.7 \pm 1.5 \mathrm{a}$ & $3 \pm 1.5 \mathrm{~b}$ & 0 \\
$\mathrm{IAA}$ & $67.5 \pm 5.5 \mathrm{a}$ & $4.5 \pm 1.5 \mathrm{a}$ & $6.9 \pm 1.5 \mathrm{c}$ & $14.6 \pm 2.3 \mathrm{a}$ & $5.5 \pm 1 \mathrm{~b}$ & 0 \\
$\mathrm{AVG}$ & $37 \pm 3.5 \mathrm{c}$ & $2 \pm 1 \mathrm{a}$ & $12.5 \pm 0.8 \mathrm{a}$ & $17.1 \pm 1.2 \mathrm{a}$ & $28.5 \pm 7.5 \mathrm{a}$ & 0 \\
$\mathrm{AgNO}_{3}$ & $33.5 \pm 0.5 \mathrm{c}$ & $2 \pm 1.2 \mathrm{a}$ & $13.7 \pm 0.9 \mathrm{a}$ & $17 \pm 1.6 \mathrm{a}$ & $33.5 \pm 4 \mathrm{a}$ & 0 \\
control & $51 \pm 5 \mathrm{~b}$ & $4 \pm 0.8 \mathrm{a}$ & $10.1 \pm 1.6 \mathrm{~b}$ & $15.4 \pm 1.2 \mathrm{a}$ & $27.5 \pm 5 \mathrm{a}$ & 0 \\
\hline
\end{tabular}

Note: values are the mean ( \pm standard error) of 45 plants. Means followed by a different letter in each column are statistically different by Duncan's new multiple range test at $p \leqq 0.05$.

\subsection{Gene Expression under Chemical Treatment}

The transcriptome data and exogenous chemical treatment results shown in our research indicated that the ethylene synthesis and signal transduction pathways play a crucial role in pumpkin flower sex expression. Thirteen $A C S$ genes in pumpkin were cloned, and gene expression patterns in different tissues were analyzed. Among them, CmaACS7 (CmaCh10G007020) was specifically expressed in female flower buds (Non-published Material 3). CmaACO1 was significantly up-regulated in FS10 in the RNA-seq data, and its female-specific expression was confirmed using qRT-PCR. CmaETR1 (CmaCh05G007380.1) and CmaEIN3 (CmaCh04G024920) were highly homologous to ETR1 and EIN3 in melon and cucumber, and were significantly highly expressed in the shoot apices of '2013-12' compared with '9-6' [37]. To examine whether these four chemicals could regulate the expression of ethylene synthesis and signal transduction genes, the expression levels of CmaACS7, CmaACO1, CmaETR1 and CmaEIN3 were detected using qRT-PCR. As shown in Figure 8, the chemicals caused different degrees of change in the expression of the 4 genes. Compared to the '2013-12' control, the expression level of CmaACS7 was elevated significantly after Ethrel and IAA treatment, whereas the mRNA level was significantly reduced after AVG treatment. $\mathrm{AgNO}_{3}$, an inhibitor of the ethylene biological response, had a nonsignificant effect on CmaACS7 expression. These results indicated that CmaACS7 expression in '2013-12' could be affected by chemical treatment. However, in the ' $9-6$ ' control, the mRNA levels of CmaACS7 were not significantly changed after the 4 chemical treatments (Figure 8A). As shown in Figure 8B, compared to those in the '2013-12' control, the mRNA levels of CmaACO1 were significantly elevated after Ethrel and IAA treatment, whereas the mRNA level was reduced after AVG treatment. Compared to the '9-6' control, the mRNA level of CmaACO1 was significantly elevated after IAA treatment but slightly reduced after AVG treatment. As shown in Figure 8C, compared to the '2013-12' control, the mRNA level of CmaETR1 was significantly elevated after Ethrel treatment, whereas the mRNA levels were reduced after $\mathrm{AVG}$ and $\mathrm{AgNO}_{3}$ treatment. Except for the IAA treatments, the tested chemicals had no effect on CmaETR1 expression compared to the ' $9-6$ ' control. As shown in Figure 8D, compared to the '2013-12' control, the mRNA levels of CmaEIN3 were significantly elevated after IAA treatment but significantly reduced after AVG treatment. Compared to the ' $9-6$ ' control, the mRNA 
level of CmaEIN3 was significantly elevated after IAA treatment, whereas the mRNA levels were reduced after Ethrel and AVG treatment. In '2013-12', most of the expression changes in CmaACS7, CmaACO1, CmaETR1 and CmaEIN3 were positively correlated with the percentage of female flowers, which indicated that exogenous chemicals can affect female flower number on the main stem through gene expression changes in the ethylene synthesis and signal transduction pathways. Compared with those in '2013-12', the variations in gene expression in '9-6', especially that of the upstream regulator CmaACS7, were small in amplitude.
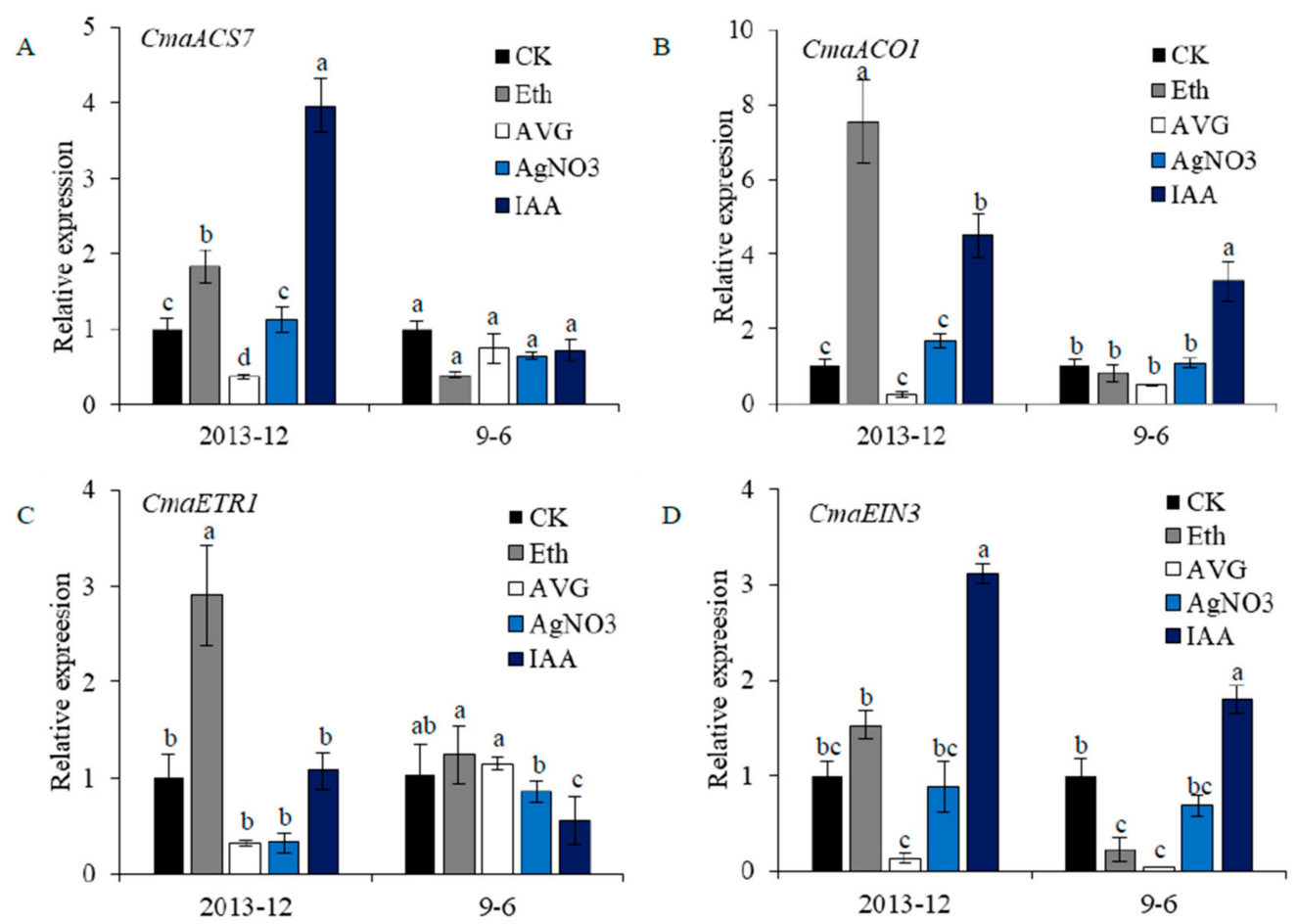

Figure 8. Expression changes of CmaACS7 (A), CmaACO1 (B), CmaETR1 (C) and CmaEIN3 (D) after Ethrel (Eth), aminoethoxyvinyl glycine (AVG), $\mathrm{AgNO}_{3}$ and indoleacetic acid (IAA) treatment. The expression level of CmaACS7, CmaACO1, CmaETR1 and CmaEIN3 were detected using qRT-PCR. Gene expression of control (CK) '2013-12' was assumed as 1 in chemical treatment '2013-12', and control (CK) '9-6' was assumed as one in chemical treatment '9-6'. Data are displayed as the ratio of expression to CmaActin with three biological replicates. Error bars represent standard error (SE). The qRT-PCR of primers used are given in Table S3. Phytohormone levels followed by the same lowercase letter are not significantly different at $p<0.05$ using SSR's test.

\subsection{CmaACS7 Expression at Different Flower Development Stages}

To examine whether CmaACS7 could involve sex expression in pumpkin, the expression of CmaACS7 in the stamen, ovary, stigma and style at different stages (S1-S7) was determined using qRT-PCR analyses. Pumpkin flower buds 7 days before flowering (dbf) (lengths of 2-4 mm) were considered to be at stage 1 (S1); $6 \mathrm{dbf}$ (lengths of 6-8 mm), stage 2 (S2); $5 \mathrm{dbf}$ (lengths of 10-12 mm), stage 3 (S3); $4 \mathrm{dbf}$ (lengths of 15-17 mm), stage 4 (S4); $3 \mathrm{dbf}$ (lengths of 20-25 mm and a yellow stigma), stage 5 (S5); $2 \mathrm{dbf}$ (lengths of 30-35 mm), stage 6 (S6); and $1 \mathrm{dbf}$, stage 7 (S7). As shown in Figure 9, CmaACS7 expression in the ovary, stigma and style decreased significantly during flower development, and the highest expression level was observed at S1. CmaACS7 expression in the stamen increased over the first five developmental stages and then decreased; the highest expression level was observed at S5. CmaACS7 expression in the stamen was much lower than that in the ovary, stigma and style throughout $\mathrm{S} 1$ to $\mathrm{S7}$, and this lower expression of CmaACS7 was significant at $\mathrm{S} 1$. The trend of CmaACS7 expression shown in Figure 9 confirmed that $\mathrm{CmaACS7}$ has an important role in early sex differentiation. 


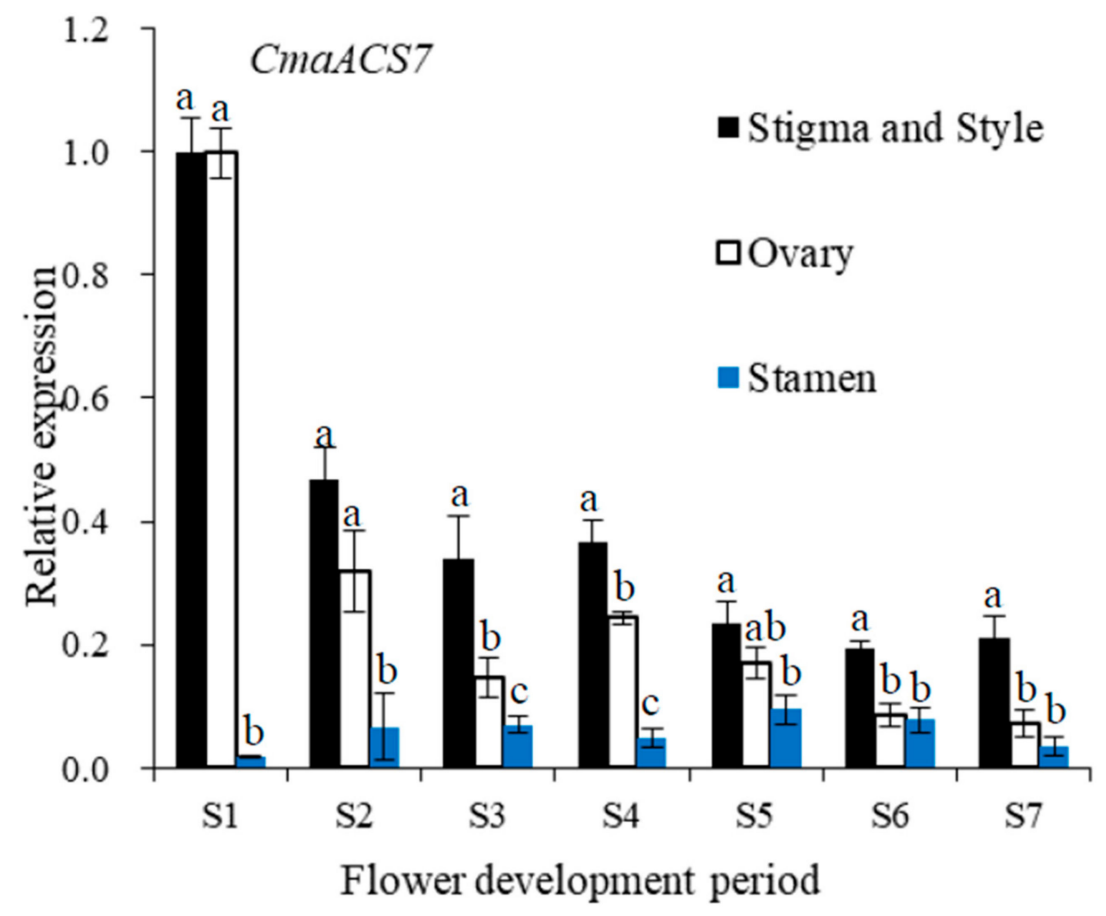

Figure 9. Relative expression of CmaACS7 at different stages (S1-S7) of '2013-12' flower development using qRT-PCR analyses. The CmaACS7 expression at $\mathrm{S} 1$ ovary was assumed as unity. The relative expression level of CmaACS7 in ovary, stigma and style was significantly high, while less expression was observed in stamen. Data are displayed as the ratio of expression to CmaActin with three biological replicates. Error bars represent standard error (SE). The qRT-PCR of primers used are given in Table S3. Phytohormone levels followed by the same lowercase letter are not significantly different at $p<0.05$ using SSR's test.

\section{Discussion}

The experiments in this study were carried out with the subandroecious line '9-6' and the trimonoecious line '2013-12'. Based on observations up to node 20 on the main stem, '9-6' produced only one or two female flowers at the top node, while '2013-12' produced approximately 10 consecutive female flowers. These two lines showed significant differences in flower sex and are therefore good materials for studying sex expression mechanisms.

The study of floral sex determination using RNA-seq has previously been reported in Cucurbitaceae plants, such as cucumber and melon [38-40], and crucial genes controlling floral sex have been cloned $[3,4,6,9-11,13]$. However, knowledge of the mechanisms and genes involved in sex expression in pumpkin is still urgently needed to provide additional information. In the present study, four sample types, i.e., shoot apices of '9-6' and '2013-12' at LS1 and LS10, were collected for RNA extraction to select DEGs that correspond to sex determination. Through transcript compilation, 871 DEGs potentially involved in pumpkin sex determination were selected. These DEGs were enriched in plant hormone signal transduction pathways, and most were related to ethylene and auxin synthesis and signal transduction. Our previous research results also showed that the endogenous ethylene and IAA contents in female flowers increased gradually to a level much higher than that in male flowers during pumpkin flower development [37]. These results confirmed that ethylene and auxin play crucial roles in pumpkin flower sex determination. According to transcriptome analyses, the major DEGs positively related to ethylene signaling exhibited high expression in the FS10 compared to the MS10 and FS1 transcriptomes (Table 2). These results indicated that ethylene signaling was more active in '2013-12' than in ' $9-6$ ', and there was a positive correlation between ethylene-activated signaling and female flower proportion. Several DEGs related to ethylene signaling were also associated with auxin, abscisic acid, cytokinin, gibberellin, jasmonic acid and salicylic acid, demonstrating the intricate 
relationships among the signaling pathways of ethylene and other hormones. Other hormonal factors might also influence the transmission of ethylene signals related to sex expression.

Exogenous chemical treatment could induce plant sexual transition. In our research, the loss of bisexual flowers in '2013-12' was accompanied by an increase in female flowers after treatment with the exogenous auxin IAA and the ethylene-releasing agent Ethrel. Some female flowers transformed from bisexual flowers retained underdeveloped stamens (Figure S2), distinct from normal female flowers. These results indicated that Ethrel and IAA treatment inhibited stamen development and led to sexual transition at the early flower development stage. Similar results were found for gynoecious and monoecious cucumber and melon [15,41,42]. $\mathrm{AgNO}_{3}$, an inhibitor of the ethylene biological response, and AVG, an inhibitor of ethylene biosynthesis, reduced the incidence of female flowers. These results are consistent with those for melon and cucumber $[43,44]$ but in contrast to the results for watermelon [26,45]. Thus, the mechanisms of sex expression in pumpkin might be similar to those in melon and cucumber.

After the 4 different chemical treatments, a wide variation (14-21.5\%) in female sex expression was observed in the trimonoecious line '2013-12'. In the subandroecious line ' $9-6$ ', the number of female flowers was not significantly changed after Ethrel, IAA, AVG or $\mathrm{AgNO}_{3}$ treatment. We noticed that the changes in flower sex in '2013-12' were greater than those in '9-6' when the lines were treated with the same chemicals at the same concentration. According to our previous research, '9-6' shows delayed abscission of ethylene-treated male flowers and a weak triple response in five-day-old seedlings compared to those of '2013-12' [27], indicating that both floral buds and seedlings had reduced sensitivity to ethylene. Therefore, we preliminarily speculated that ethylene signaling could be transduced in '9-6' plants but was much weaker than that in '2013-12'. This result is probably because an important gene involved in ethylene accumulation or signal multiplication cannot act normally in ' $9-6$ '.

In '2013-12', the expression of CmaACS7, CmaACO1 and CmaETR1 was significantly promoted by Ethrel. Ethrel could increase ethylene level and amplify ethylene signaling in the apex by upregulating the expression of ethylene synthesis and ethylene receptor genes, leading to a significant increase in female flowers (a $21.5 \%$ increase) and advancing the first female flower appearance. After IAA treatment, '2013-12' showed a significant increase (16.5\%) in female sex expression, a significant decrease (22\%) in bisexuality, and advancement of the first female flower appearance; Ethrel treatment led to similar tendencies. The expression of ethylene biosynthetic genes (CmaACS7, CmaACO1) and ethylene signaling genes ( $\mathrm{CmaEIN3)}$ was significantly increased. IAA treatment promoted ethylene production and the expression of ethylene-related genes. Similar conclusions have been reached in zucchini (Cucurbita pepo L.) and cucumber $[46,47]$. Auxins can induce ethylene production by stimulating the expression of $A C S$, causing fruit softening [48]. In our research, IAA treatment also induced a much higher level of CmaACS7 expression. We suggest that IAA might affect pumpkin sex expression by inducing CmaACS7 expression and indirectly affecting ethylene production. Ethyleneinsensitive (EIN) 3 is continuously degraded in plant cells [49], and the stability of EIN3 is regulated by the $26 \mathrm{~S}$ proteasome $[50,51]$. IAA might affect the $26 \mathrm{~S}$ proteasome to increase the stability of EIN3. Both AVG and $\mathrm{AgNO}_{3}$ treatment inhibited female sex expression and delayed the first female flower in '2013-12', but they had different effects on gene expression. AVG treatment reduced the expression of the ethylene synthesis genes $\mathrm{CmaACS7}$ and $\mathrm{CmaACO1}$, whereas $\mathrm{AgNO}_{3}$ reduced the expression of only the ethylene signal transduction gene. These results indicated that reduced ethylene levels and weakened ethylene signaling intensity could affect pumpkin sex expression. 
Ethrel caused no significant changes in the expression of ethylene synthesis or receptor genes compared to the '9-6' control, which indicated that '9-6' plant had lacked its normal function of responding to Ethrel signal. It is interesting that, although the expression of CmaACO1 and CmaEIN3 changed under IAA treatment in ' $9-6$ ', the percentage of female flowers and the node of first female appearance were not significantly affected compared with those of the '9-6' control. IAA had no influence on the expression of the upstream regulator CmaACS7. In fact, variations in CmaACS7 expression were not obvious after Ethrel or other chemical treatments in '9-6', which corresponded to no significantly changed number of female flowers. These results indicate that the expression level of CmaACS7 plays a crucial role in sex expression in pumpkin. Activated ACS can be induced by ethylene and IAA to regulate downstream genes in cucumber [4]. In our research, CmaACS7 in pumpkin '9-6' lost its capability to respond to IAA or ethylene after chemical treatment. The sequences of CmaACS7 were highly similar to those of CsACS2 (87.47\%) and CmACS7 (87.47\%) [4,8]. Closely linked markers of CmaACS7 were developed to analyze $200 \mathrm{~F}_{2}$ individuals derived from a cross of '2013-12' and '9-6'. Notably, markers closely linked to CmaACS7 were not genetically linked to female flower proportion. We speculated that another key gene influencing CmaACS7 response might be mutated in '9-6'.

Using $F_{2}$ individuals derived from a cross between the trimonoecious line '2013-12' and the subandroecious line ' $9-6$ ', a gene controlling high female flower proportion (higher than $45 \%$ up to node 20) was mapped and located in a narrow region. Several transcription factor genes were found in the located region, which did not contain any genes directly associated with ethylene synthesis and signaling transduction. Thus, we predicted that a transcription factor gene could be stimulated by hormone signaling (ethylene and IAA) and then the transcription factor protein could specifically be combined with CmaACS7 promoter to led high expression of CmaACS7 gene in '2013-12' flowers. When the sequencing of transcription factor gene changed, CmaACS7 gene could not be regulated. So CmaACS7 had lost its positive feedback capability with respect to the ethylene pathway in '9-6'. This phenomenon could explain the different sex expression between pumpkin lines '2013-12' and ' $9-6$ ', and ethylene sensitivity was reduced in ' $9-6$ '. Further research about the lack of increase female flowers after chemical treatment in ' $9-6$ ' is being planned to carry in our lab. The transcriptome data and chemical treatment results in our research benefited for key genes selection and gene interactions research regulated to pumpkin sex expression.

\section{Materials and Methods}

\subsection{Plant Materials}

The experiment was carried out with the subandroecious inbred line ' $9-6$ ' and the trimonoecious inbred line '2013-12' (Figure 1). The seeds of ' $9-6$ ' and '2013-12' were germinated at $30^{\circ} \mathrm{C}$ in the dark for $36 \mathrm{~h}$ after being treated with $55^{\circ} \mathrm{C}$ water for $8 \mathrm{~h}$ and then transplanted to greenhouse breeding plots at Northeast Agricultural University. Four-leaf-stage seedlings were transferred to a greenhouse, and the required irrigation and fertilizer were applied under natural photoperiodic conditions in the spring of 2017.

\subsection{RNA Extraction and RNA-Seq Processing}

In subandroecious line ' $9-6$ ', shoots at LS1 contained only male flower buds, whereas those at LS10 contained male flower buds and one or two female flower buds. In trimonoecious line '2013-12', shoots at LS1 contained male flower buds and one or two bisexual flower buds, and those at LS10 contained only female flower buds. There were obvious sex expression differences in FS1 vs. FS10 and in MS10 vs. FS10, which could explore the sex expression related genes. There was no significant differences were observed in MS1 vs. MS10 and MS1 vs. FS1, which could remove DEGs by virtue of different genetic background.

Young shoot apices of '9-6' and '2013-12' at LS1 and LS10 were collected for RNA extraction to study the transcriptome (four sample types with three biological replicates, 10 plants for each sample). All samples were immediately frozen in liquid $\mathrm{N}_{2}$ and were stored at $-70^{\circ} \mathrm{C}$ for RNA-seq analysis. 
Total RNA was were extracted using TRIzol reagent (Invitrogen, USA) and were treated with RNase-free DNase. mRNA was isolated from the total RNA using Dynabeads Oligo (dT) (Invitrogen Dynal), fragmented into small pieces and then copied into cDNA using reverse transcriptase. After purification, the cDNA fragments were connected using sequencing adapters. The fragments were sequenced from directions on an Illumina HiSeq ${ }^{\mathrm{TM}} 2000$ System (Illumina, San Diego, CA), and then the quality and purity of the constructed library were determined using an Agilent 2100 Bioanalyzer (Agilent Technologies, Palo Alto, CA, USA.) [52].

\subsection{RNA-Seq Assembly, Annotation and Transcriptome Sequence Analysis}

The raw reads from each library were assembled separately through base-calling analysis. After quality assessment using FASTQC software [53], the trimmed adapter sequences and the low-quality reads were removed using NGS QC TOOLKIT v2.3.3 [54]. The high-throughput clean reads were mapped to the Cucurbita maxima (Rimu) reference genome (ftp://www.cucurbitgenomics.org/pub/cucurbit/genome/ Cucurbita_maxima/v1.1/Cmaxima_v1.1.chr.fa.gz) by the TopHat2 program [55]. The default settings were used for the remaining parameters. The uniformity and the saturation of sequencing data were analyzed based on the alignment results. Functional annotation of unigenes was performed by searching against the nonredundant (NR) (ftp://ftp.ncbi.nih.gov/blast/db), Swiss-Prot (http://www.uniprot.org/downloads) and clusters of orthologous groups for eukaryotic complete genomes (KOG) (ftp://ftp.ncbi.nih.gov/pub/ COG/KOG/kyva) databases using BLAST with an E-value of $1 \mathrm{e}^{-5}$.

Unigene expression was determined based on fragments per kilobase per million reads (FPKM) [56]. To discover the relationships among the samples, principal component analysis (PCA) was performed using unigene expression. To study the similarity between samples, sample-to-sample distances were calculated using the Euclidean distance method. The samples belonging to the same experimental conditions were close in distance and grouped together preferentially.

Differentially expressed genes (DEGs) were identified with an adjusted $p$-value $<0.05$ for multiple tests using the Benjamini-Hochberg method [57] for controlling the false discovery rate. The DEGs were functionally annotated by mapping onto GO classifications (using the adjusted p-value; http://www.geneontology.org/) using Blast2GO [58]. Three categories of GO annotations, i.e., biological process, molecular function, and cellular component, were analyzed. After the hypergeometric test, Bonferroni correction was employed for P-value correction with a cut-off of 0.05 . KEGG pathways were identified and mapped according to $p$-values by searching against the KEGG database (http://www.genome.jp/kegg/pathway.html) [59].

\subsection{Quantitative RT-PCR Analysis}

Shoot apices of '2013-12' at LS1 and LS10 were collected, and RNA was extracted for real-time quantitative polymerase chain reaction (qRT-PCR) analysis. cDNAs were reverse transcribed using $2 \mu \mathrm{g}$ of total RNA with the PrimeScript RT Reagent Kit (Takara, Dalian, China). For qRT-PCR, $20 \mu \mathrm{L}$ samples were run in triplicate on an ABI Prism 7000 Sequence Detection System and Applied Biosystems software using SYBR Green PCR Master Mix (Applied Biosystems, Carlsbad, CA, USA). Thermal cycling was performed using an initial denaturation step of $95^{\circ} \mathrm{C}$ for $3 \mathrm{~min}$ followed by 40 cycles at $95^{\circ} \mathrm{C}$ for $10 \mathrm{~s}$, annealing temperature for $20 \mathrm{~s}$, and $72{ }^{\circ} \mathrm{C}$ for $20 \mathrm{~s}$. The relative expression levels of the genes were calculated by the $2^{-\Delta \Delta \mathrm{Ct}}$ method and were normalized to the control gene actin. The primer sequences used in qRT-PCR are listed in Table S3.

\subsection{Plant Hormone Treatments}

To study the effects of ethylene and auxin on the sex of $C$. maxima, 4 different chemical solutions, i.e., $100 \mathrm{mg} / \mathrm{L}$ 2-chloroethylphosphonic acid (Ethrel) (an ethylene-releasing agent), $100 \mathrm{mg} / \mathrm{L}$ aminoethoxyvinyl glycine (AVG) (an inhibitor of ethylene biosynthesis), $200 \mathrm{mg} / \mathrm{L} \mathrm{AgNO} 3$ (an inhibitor of ethylene biological response), and $200 \mathrm{mg} / \mathrm{L} \mathrm{IAA}$, were added to $\mathrm{H}_{2} \mathrm{O}$ containing $0.1 \%(v / v)$ Tween 20 were applied as treatments, and $\mathrm{ddH}_{2} \mathrm{O}$ with $0.1 \%$ Tween 20 was used as the control. The shoot apices 
of '2013-12' and '9-6' at the four-true-leaf stage (S4) were sprayed four times (continuously) with these chemical solutions once per day, and each treatment consisted of 15 plants with three biological replicates. After treatment for $1 \mathrm{~d}$, the shoot apices of '2013-12' and ' $9-6$ ' that had been subjected to the different chemical solutions were selected for transcript level detection. The primer sequences used in qRT-PCR are listed in Table S3. The sex of each flower up to node 20 on the main stem was determined as male, female or bisexual, and the first female flower node was also documented.

\subsection{Gene expression at Different Stages of Flower Development}

Pumpkin flower buds were divided into seven different stages of flower development. Buds with lengths of 2-4 mm were considered to be at stage 1 (S1); those with lengths of 6-8 $\mathrm{mm}$, stage 2 (S2); 10-12 mm, stage 3 (S3); 15-17 mm, stage 4 (S4); 20-25 mm and a yellow stigma, stage 5 (S5); 30-35 mm, stage 6 (S6); and those one day before flowering were considered to be at stage 7 (S7). Male and female flower buds from S1 to S7 were collected from the trimonoecious line '2013-12', and the stamen, ovary, stigma and style were detached from male and female flower buds for qRT-PCR. The morphologies of female and male flower buds at S1-S7 are shown in Figure S3.

\section{Conclusions}

In the present study, we investigated different transcript expression patterns between trimonoecious and subandroecious pumpkins. The DEGs between shoot apices containing male buds and female buds were mainly enriched in the ethylene and auxin synthesis and signal transduction pathways. The numbers of female flowers in '2013-12' changed significantly, while the numbers in '9-6' changed slightly after exogenous hormone treatments. The expression levels of CmaACS7, CmaACO1, CmaETR1 and CmaEIN3 were positively correlated with the number of female flowers in '2013-12', and IAA might affect pumpkin sex expression by inducing CmaACS7 expression and indirectly affecting ethylene production. The variations in gene expression in '9-6', especially CmaACS7, were small in amplitude. CmaACS7 expression in the ovary, stigma and style in flower development also indicated that CmaACS7 plays an important role in sex differentiation. Based on the expression of key genes, a possible reason for the different sex expression between pumpkin lines '2013-12' and '9-6' was determined.

Supplementary Materials: The Supplementary Materials are available online at http://www.mdpi.com/1422-0067/ 20/13/3185/s1.

Author Contributions: Y.W. performed data analysis, preparing the manuscript. C.Y. and B.Z. contributed to chemical treat and collecting phenotypic characteristics. C.W. contributed to RNA extraction and qRT-PCR. W.X. contributed to growing plants. C.C. contributed to providing experimental material. S.Q., the corresponding author, oversaw all activities related to the project implementation and manuscript development. All authors reviewed the manuscript.

Funding: This research was supported by grants from the National Key Research and Development Program of China (2018YFD0100706), Ministry of Science and Technology, China; the Heilongjiang Province Foundation for Returness (LC2016012), Heilongjiang, China; the Natural Science Foundation of Heilongjiang Province of China (C2018027), Heilongjiang, China; and the Youth Foundation of Northeast Agricultural University (17QC08), Northeast Agricultural University, China.

Acknowledgments: We thank American Journal Experts (AJE) for polishing language of the manuscript.

Conflicts of Interest: The authors declare that the research was conducted in the absence of any commercial or financial relationships that could be construed as a potential conflict of interest. 


\section{Abbreviations}

$\begin{array}{ll}\text { ACC } & \text { 1-aminocyclopropane-1-carboxylate } \\ \text { ACO } & \text { 1-aminocyclopropane-1-carboxylate oxidase } \\ \text { ACS } & \text { 1-aminocyclopropane-1-carboxylate synthetase } \\ \text { ERF } & \text { Ethylene-responsive factor } \\ \text { EIN } & \text { Ethylene- insensitive } \\ \text { WEI } & \text { Weak ethylene insensitive } \\ \text { CTR } & \text { Constitutive triple response } \\ \text { RNA-seq } & \text { RNA sequencing } \\ \text { C. maxima } & \text { Cucurbita maxima } \\ \text { C. pepo } & \text { Cucurbita pepo } \\ \text { C. moschata } & \text { Cucurbita moschata } \\ \text { GO } & \text { Gene ontology } \\ \text { KEGG } & \text { Kyoto Encyclopedia of Genes and Genomes } \\ \text { FPKM } & \text { Fragments per kilobase of exon per million fragments mapped } \\ \text { bp } & \text { Base pairs } \\ \text { DEGs } & \text { Differentially expressed genes } \\ \text { MAPK } & \text { Mitogen-activated protein kinase } \\ \text { LS1 } & \text { One-true-leaf stage } \\ \text { LS10 } & \text { 10-leaf stage } \\ \text { qRT-PCR } & \text { Quantitative reverse transcription polymerase chain reaction } \\ \text { PCA } & \text { Principal component analysis } \\ \text { AVG } & \text { Aminoethoxyvinyl glycine } \\ \text { IAA } & \text { Indoleacetic acid } \\ & \end{array}$

\section{References}

1. Ekaterina, P.; Holly, A.L.; Sue, A.H.; Rebecca, G. Effect of modified endogenous ethylene production on sex expression, bisexual flower development and fruit production in melon (Cucumis melo L.). Sex. Plant Reprod. 2005, 18, 131-142.

2. Kater, M.M.; Franken, J.; Carney, K.J.; Colombo, L.; Angenent, G.C. Sex determination in the monoecious species cucumber is confined to specific floral whorls. Plant Cell 2001, 13, 481-493. [CrossRef] [PubMed]

3. Saito, S.; Fujii, N.; Miyazawa, Y.; Yamasaki, S.; Matsuura, S.; Mizusawa, H.; Fujita, Y.; Takahashi, H. Correlation between development of female flower buds and expression of the CS-ACS2 gene in cucumber plants. J. Exp. Bot. 2007, 58, 2897-2907. [CrossRef] [PubMed]

4. Li, Z.; Huang, S.; Liu, S.; Pan, J.; Zhang, Z.; Tao, Q.; Shi, Q.; Jia, Z.; Zhang, W.; Chen, H.; et al. Molecular isolation of the $M$ gene suggests that a conserved-residue conversion induces the formation of bisexual flowers in cucumber plants. Genetics 2009, 182, 1381-1385. [CrossRef] [PubMed]

5. Boualem, A.; Troadec, C.; Camps, C.; Lemhemdi, A.; Morin, H.; Sari, M.; Fraenkel-Zagouri, R.; Kovalski, I.; Dogimont, C.; Perl-Treves, R.; et al. A cucurbit androecygene reveals how unisexual flowers develop and dioecy emerges. Plant Genetics 2015, 350, 688-691.

6. Zhang, Z.; Mao, L.; Chen, H.; Bu, F.; Li, G.; Sun, J.; Li, S.; Sun, H.; Jiao, C.; Blakely, R.; et al. Genome-wide mapping of structural variations reveals a copy number variant that determines reproductive morphology in cucumber. Plant Cell 2015, 27, 1595-1604. [CrossRef] [PubMed]

7. Yang, S.F.; Hoffman, N.E. Ethylene biosynthesis and its regulation in higher plants. Annu. Rev. Plant Physiol. 2003, 35, 155-189. [CrossRef]

8. Boualem, A.; Fergany, M.; Fernandez, R.; Troadec, C.; Martin, A.; Morin, H.; Sari, M.A.; Collin, F.; Flowers, J.M.; Pitrat, M.; et al. A conserved mutation in an ethylene biosynthesis enzyme leads to andromonoecy in melons. Science 2008, 321, 836-838. [CrossRef]

9. Boualem, A.; Troadec, C.; Kovalski, I.; Sari, M.A.; Perl-Treves, R.; Bendahmane, A. A conserved ethylene biosynthesis enzyme leads to andromonoecy in two Cucumis species. PLoS ONE 2009, 4, e6144. [CrossRef] 
10. Martin, A.; Troadec, C.; Boualem, A.; Rajab, M.; Fernandez, R.; Morin, H.; Pitrat, M.; Dogimont, C.; Bendahmane, A. A transposon-induced epigenetic change leads to sex determination in melon. Nature 2009, 461, 1135-1138. [CrossRef]

11. Adnane, B.; Afef, L.; Marie-Agnes, S.; Sarah, P.; Christelle, T.; Fadi, A.; Ilknur, S.; Nebahat, S.; Catherine, D.; Abdelhafid, B. The androandroecious sex determination gene predates the separation of Cucumis and Citrullus Genera. PLOS ONE 2016, 11, e0155444.

12. Ji, G.; Zhang, J.; Zhang, H.; Sun, H.; Gong, G.; Shi, J.; Tian, S.; Guo, S.; Ren, Y.; Shen, H.; et al. Mutation in the gene encoding 1-aminocyclopropane-1-carboxylate synthase 4 (CitACS4) led to andromonoecy in watermelon. J. Integr. Plant Biol. 2016, 9, 762-765. [CrossRef] [PubMed]

13. Knopf, R.R.; Trebitsh, T. The female-specific Cs-ACS1G gene of cucumber. A case of gene duplication and recombination between the non-sex-specific 1-aminocyclopropane-1-carboxylate synthase gene and a branched-chain amino acid transaminase gene. Plant Cell Physiol. 2006, 47, 1217-1228. [CrossRef] [PubMed]

14. Chen, H.; Sun, J.; Li, S.; Cui, Q.; Zhang, H.; Xin, F.; Wang, H.; Lin, T.; Gao, D.; Wang, S.; et al. An ACC oxidase gene essential for cucumber carpel development. Mol. Plant. 2016, 9, 1315-1327. [CrossRef] [PubMed]

15. Yamasaki, S.; Fujii, N.; Takahashi, H. The ethylene-regulated expression of CS-ETR2 and CS-ERS genes in cucumber plants and their possible involvement with sex expression in flowers. Plant Cell Physiol. 2000, 41, 608-616. [CrossRef] [PubMed]

16. Wang, D.; Li, F.; Duan, Q.; Han, T.; Xu, Z.; Bai, S. Ethylene perception is involved in female cucumber flower development. Plant J. 2010, 61, 862-872. [CrossRef] [PubMed]

17. Tao, Q.; Niu, H.; Wang, Z.; Zhang, W.; Wang, H.; Wang, S.; Zhang, X.; Li, Z. Ethylene responsive factor ERF110 mediates ethylene-regulated transcription of a sex determination-related orthologous gene in two Cucumis species. J. Exp. Bot. 2018, 25, 2953-2965. [CrossRef]

18. Pan, J.; Wang, G.; Wen, H.; Du, H.; Lian, H.; He, H.; Pan, J.; Cai, R. Differential gene expression caused by the $F$ and $M$ Loci provides insight into ethylene-mediated female flower differentiation in cucumber. Front Plant Sci. 2018, 9. [CrossRef]

19. Peñaranda, A.; Payan, M.C.; Garrido, D.; Gómez, P.; Jamilena, M. Production of fruits with attached flowers in zucchini squash is correlated with the arrest of maturation of female flowers. J. Hortic. Sci. Biotech. 2007, 82, 579-584. [CrossRef]

20. Kubicki, B. Androecious strains of Cucurbita pepo L. Genet. Pol. 1970, 11, 45-51.

21. Dossey, B.F.; Bemis, W.P.; Scheerens, J.C. Genetic control of gynoecy in the buffalo gourd. J. Hered. 1981, 72, $355-356$. [CrossRef]

22. Manzano, S.; Dominguez, V.J.; Garrido, D.; Gómez, P.; Jamilena, M. A recessive gene conferring ethylene insensitivity and androecy in Cucurbita pepo. Cucurbitaceae Ixth Eucarpia Meeting on Genetics and breeding of Cucurbitaceae. INRA 2008, 563-567.

23. Manzano, S.; Martınez, C.; Domınguez, V.; Avalos, E.; Garrido, D.; Gómez, P.; Jamilena, M. A major gene conferring reduced ethylene sensitivity and maleness in Cucurbita pepo. J. Plant Growth Regul. 2010, 29, 73-80. [CrossRef]

24. Manzano, S.; Martınez, C.; Gomez, P.; Garrido, D.; Jamilena, M. Cloning and characterisation of two CTR1-like genes in Cucurbita pepo: Regulation of their expression during male and female flower development. Sex Plant Reprod. 2010, 23, 301-313. [CrossRef] [PubMed]

25. Manzano, S.; Martınez, C.; Megías, Z.; Garrido, D.; Picó, B.; Jamilena, M. Involvement of ethylene biosynthesis and signalling in the transition from male to female flowering in the monoecious Cucurbita pepo. J. Plant Growth Regul. 2013, 32, 789-798. [CrossRef]

26. Manzano, S.; Martínez, C.; García, J.M.; Megías, Z.; Jamilena, M. Involvement of ethylene in sex expression and female flower development in watermelon (Citrullus lanatus). Plant Physiol. Biochem. 2014, 85, 96-104. [CrossRef]

27. Yang, W. Mapping and candidate gene analysis of strong female characteristic in Cucurbita maxima Duch. Master's Thesis, Hebei University of Engineering, Hebei, China, December 2016.

28. Blanca, J.; Cañizares, J.; Roig, C.; Ziarsolo, P.; Nuez, F.; Picó, B. Transcriptome characterization and high throughput SSRs and SNPs discovery in Cucurbita pepo (Cucurbitaceae). BMC Genom. 2011, 12, 104. [CrossRef] 
29. Esteras, C.; Gómez, P.; Monforte, A.J.; Blanca, J.; Vicente-Dólera, N.; Roig, C.; Nuez, F.; Picó, B. High-throughput SNP genotyping in Cucurbita pepo for map construction and quantitative trait loci mapping. BMC Genom. 2012, 13, 80-101. [CrossRef]

30. Wu, T.; Luo, S.; Wang, R.; Zhong, Y.; Xu, X.; Lin, Y.; He, X.; Sun, B.; Huang, H. The first Illumina-based de novo transcriptome sequencing and analysis of pumpkin (Cucurbita moschata Duch.) and SSR marker development. Mol. Breeding 2014, 34, 1437-1447. [CrossRef]

31. Summers, C.F.; Gulliford, C.M.; Carlson, C.H.; Lillis, J.A.; Carlson, M.O.; Cadle-Davidson, L.; Gent, D.H.; Smart, C.D. Identification of genetic variation between obligate plant pathogens Pseudoperonospora cubensis and P. humuli using RNA sequencing and genotyping-by-sequencing. PLoS ONE 2015, 10, e0143665. [CrossRef]

32. Wyatt, L.E.; Strickler, S.R.; Mueller, L.A.; Mazourek, M. An acorn squash (Cucurbita pepo ssp. ovifera) fruit and seed transcriptome as a resource for the study of fruit traits in Cucurbita. Hortic. Res. 2015, 2. [CrossRef] [PubMed]

33. Wyatt, L.E.; Strickler, S.R.; Mueller, L.A.; Mazourek, M. Comparative analysis of Cucurbita pepo metabolism throughout fruit development in acorn squash and oilseed pumpkin. Hortic. Res. 2016, 3, 16045. [CrossRef] [PubMed]

34. Xanthopoulou, A.; Ganopoulos, I.; Psomopoulos, F.; Manioudaki, M.; Moysiadis, T.; Kapazoglou, A.; Osathanunkul, M.; Michailidou, S.; Kalivas, A.; Tsaftaris, A.; et al. De novo comparative transcriptome analysis of genes involved in fruit morphology of pumpkin cultivars with extreme size difference and development of EST-SSR markers. Gene 2017, 622, 50-66. [CrossRef] [PubMed]

35. Carvajal, F.; Rosales, R.; Palma, F.; Manzano, S.; Canizares, J.; Jamilena, M.; Garrido, D. Transcriptomic changes in Cucurbita pepo fruit after cold storage: Differential response between two cultivars contrasting in chilling sensitivity. BMC Genom. 2018, 19, 125. [CrossRef] [PubMed]

36. Guo, W.L.; Chen, B.H.; Chen, X.J.; Guo, Y.Y.; Yang, H.L.; Li, X.Z.; Wang, G.Y. Transcriptome profiling of pumpkin (Cucurbita moschata Duch.) leaves infected with powdery mildew. PLoS ONE 2018, 13, e0190175. [CrossRef] [PubMed]

37. Yang, G.; Yang, X.; Wang, Y.; Xu, W.; Cui, C.; Qu, S. Content changes of endogenous hormones and polyamine during flower development in pumpkin. China Sciencepap. 2016, 11, 2096-2099.

38. Guo, S.; Zheng, Y.; Joung, Y.; Liu, S.; Zhang, Z.; Crasta, O.; Sobral, B.W.; Xu, Y.; Huang, S.; Fei, Z. Transcriptome sequencing and comparative analysis of cucumber flowers with different sex types. BMC Genom. 2010, 11, 384. [CrossRef] [PubMed]

39. Wu, T.; Qin, Z.; Zhou, X.; Feng, Z.; Du, Y. Transcriptome profile analysis of floral sex determination in cucumber. J. Plant Physiol. 2010, 167, 905-913. [CrossRef] [PubMed]

40. Gao, P.; Sheng, Y.; Luan, F.; Ma, H.; Liu, S. RNA-Seq transcriptome profiling reveals differentially expressed genes involved in sex expression in melon. Crop Sci. 2016, 55, 1686-1695. [CrossRef]

41. Yamasaki, S.; Fujii, N.; Matsuura, S.; Mizusawa, H.; Takahashi, H. The M locus and ethylene-controlled sex determination in andromonoecious cucumber plants. Plant Cell Physiol. 2001, 42, 608-619. [CrossRef]

42. Martínez, C.; Manzano, S.; Megías, Z.; Barrera, A.; Boualem, A.; Garrido, D.; Bendahmane, A.; Jamilena, M. Molecular and functional characterization of CpACS27A gene reveals its involvement in monoecy instability and other associated traits in squash (Cucurbita pepo L.). Planta 2014, 239, 1201-1215. [CrossRef] [PubMed]

43. Li, X.; Wei, B.; Liu, A.; Zhang, J.; Feng, H. Female flowers were induced by ethephon in andromonecious Cucumis melo L. China Veg. 2010, 4, 67-70. (In Chinese)

44. Rudich, J.; Halevy, A.; Kedar, N. Increase in femaleness of three cucurbits by treatment with ethrel, an ethylene releasing compound. Planta 1969, 86, 69-76. [CrossRef] [PubMed]

45. Zhang, J.; Shi, J.; Ji, G.; Zhang, H.; Gong, G.; Guo, S.; Ren, Y.; Fan, J.; Tian, S.; Xu, Y. Modulation of sex expression in four forms of watermelon by gibberellin, ethephone and silver nitrate. Hortic. Plant J. 2017, 3, 91-100. [CrossRef]

46. Li, Z.; Wang, S.; Tao, Q.; Pan, J.; Si, L.; Gong, Z.; Cai, R. A putative positive feedback regulation mechanism in CsACS2 expression suggests a modified model for sex determination in cucumber (Cucumis sativus L.). J. Exp. Bot. 2012, 63, 4475-4484. [CrossRef]

47. Martínez, C.; Manzano, S.; Megías, Z.; Garrido, D.; Picó, B.; Jamilena, M. Involvement of ethylene biosynthesis and signaling in fruit set and early fruit development in zucchini squash (Cucurbita pepo L.). BMC Plant Biol. 2013, 13, 139. [CrossRef] 
48. Tatsuki, M.; Nakajima, N.; Fujii, H.; Shimada, T.; Nakano, M.; Hayashi, K.; Hayama, H.; Yoshioka, H.; Nakamura, Y. Increased levels of IAA are required for system 2 ethylene synthesis causing fruit softening in peach (Prunus persica L. Batsch). J. Exp. Bot. 2013, 64, 1049-1059. [CrossRef]

49. Yanagisawa, S.; Yoo, S.D.; Sheen, J. Differential regulation of EIN3 stability by glucose and ethylene signaling in plants. Nature 2003, 425, 521-525. [CrossRef]

50. Guo, H.W.; Ecker, J.R. Plant responses to ethylene gas are mediated by SCF (EBFl/EBF2)-dependent proteolysis of EIN3 transcription factor. Cell 2003, 115, 667-677. [CrossRef]

51. Potuschak, T.; Lechner, E.; Parmentier, Y.; Yanagisawa, S.; Grava, S.; Koncz, C.; Genschik, P. EIN3-dependent regulation of plant ethylene hormone signaling by two Arabidopsis F box proteins: EBF1 and EBF2. Cell 2003, 115, 679-689. [CrossRef]

52. Grabherr, M.G.; Haas, B.J.; Yassour, M.; Levin, J.Z.; Thompson, D.A.; Amit, I.; Adiconis, X.; Fan, L.; Raychowdhury, R.; Zeng, Q.; et al. Trinity: Reconstructing a full-length transcriptome without a genome from RNA-Seq data. Nat. Biotechnol. 2011, 29, 644-652. [CrossRef] [PubMed]

53. Cock, P.J.A.; Fields, C.J.; Goto, N.; Heuer, M.L.; Rice, P.M. The Sanger FASTQ file format for sequences with quality scores, and the Solexa/Illumina FASTQ variants. Nucleic Acids Res. 2010, 38, 1767-1771. [CrossRef] [PubMed]

54. Patel, R.K.; Jain, M. NGS QC Toolkit: A toolkit for quality control of next generation sequencing data. PLoS ONE 2012, 7, e30619. [CrossRef] [PubMed]

55. Kim, D.; Pertea, G.; Trapnell, C.; Pimentel, H.; Kelley, R.; Salzberg, S.L. TopHat2: Accurate alignment of transcriptomes in the presence of insertions, deletions and gene fusions. Genome Biol. 2013, 14, 1-13. [CrossRef] [PubMed]

56. Trapnell, C.; Williams, B.A.; Pertea, G.; Mortazavi, A.; Kwan, G.; Baren, M.J.; Salzberg, S.L.; Wold, B.J.; Pachter, L. Transcript assembly and quantification by RNA-Seq reveals unannotated transcripts and isoform switching during cell differentiation. Nat. Biotechnol. 2010, 28, 511-515. [CrossRef] [PubMed]

57. Benjamini, Y.; Hochberg, Y. Controlling the false discovery rate: A practical and powerful approach to multiple testing. J. R. Stat. Soc. Ser. B 1995, 57, 289-300. [CrossRef]

58. Conesa, A.; Gotz, S.; Garcia-Gomez, J.M.; Terol, J.; Talon, M.; Robles, M. Blast2GO: A universal tool for annotation, visualization and analysis in functional genomics research. Bioinformatics 2005, 21, 3674-3676. [CrossRef] [PubMed]

59. Young, M.D.; Wakefield, M.J.; Smyth, G.K.; Oshlack, A. Gene ontology analysis for RNA-seq: Accounting for selection bias. Genome Biol. 2010, 11, 14-26. [CrossRef] [PubMed] 